\title{
Current Cultures in Threatening, Comforting, and Challenging Ecologies
}

\author{
Evert Van de Vliert' \\ Faculty of Behavioral and Social Sciences \\ University of Groningen, The Netherlands
}

\section{Abstract}

Places of residence have multiple, yet largely unintegrated, cultural characteristics. Here I make a distinction between human environments that offer demanding winters or summers together with collective poverty (threatening ecologies), undemanding temperate climates irrespective of income per head (comforting ecologies), and demanding winters or summers together with collective wealth (challenging ecologies). After reviewing prior research into cultural characteristics under these environmental conditions, I am reporting a climato-economic study of we/they discrimination across 95 nations. Together, these investigations show that threatening ecologies are prone to mental ill-being, bureaucratic organizing, press repression, autocratic politics, survival goals, societal collectivism, and relatively strong we/they discrimination. By contrast, challenging ecologies are prone to mental well-being, organic organizing, press freedom, democratic politics, self-expression goals, societal individualism, and relatively weak we/they discrimination. In between these extremes, comforting ecologies are prone to intermediate cultural realities.

Keywords: challenges, climato-economic theory, cultural anthropology, threats, human ecology

\section{Introduction}

Dotted around the globe are many ancient buildings and structures left behind by societies that collapsed or vanished. Not infrequently, these monuments provide stark evidence of the indisputable fact that all living species can easily be frozen or boiled to death, and of the broader reality that humans thrive in temperate climates and are in danger to the extent they are living in colder or hotter regions of the planet. Colder-than-temperate winters and hotter-thantemperate summers entail larger deviations from physiological homeostasis and

$1 \quad$ Author contact: E.Van.de.Vliert@rug.nl. 
thermal comfort, fewer nutritional resources due to poorer flora and fauna, and greater health problems (Van de Vliert, 2009, 2013a). In these harsher climates, humans must ceaselessly solve problems of extreme temperatures, shrinking food and drink supplies, and lurking diseases.

In order to adapt culturally to thermal climate and other ecological conditions, our ancestors started to obtain and store property. With the advent of agriculture this was first in the form of stores of food and domesticated animals. Property allowed trading. Trading led to the invention of money, which can be stored longer and more easily than agricultural products, and which can solve a fantastic variety of climatic problems. The miraculous achievements of money as a climate-compensating tool are in no way tied to a specific ethnic group, a particular geographic area, or a certain period in time. As a rule, liquid cash and illiquid capital can buy all the necessities of life, including clothing and housing, heat and cold, food and drink, cure and care. Slowly but surely, the availability of wealth resources has become the essential solution for the basic problem of survival when living away from temperate climates.

This paper takes stock of recent progress in predicting adaptations of national cultures to climato-economic ecologies, and then seeks an empirical answer to the question whether this line of theory building can be extended to the highly relevant phenomenon of we/they discrimination. First, I propose that threatening, comforting, and challenging interactions of climatic demands and wealth resources be studied as partial roots of human functioning. Second, I provide an overview of study results that established links between the three types of habitats and three patterns of characteristics of culture. The empirical section, finally, describes how I integrated separate measures of ingroup love and outgroup hate into a single estimate of the degree of we/they discrimination, and conducted a further climato-economic analysis across 95 nations, the results of which are reported here for the first time.

\section{Climato-economic ecologies}

\section{Theory: Threats versus challenges}

Points of departure. This article is not about evolution by natural selection. Nonetheless, it has deep roots in the human habit to continuously appraise the environmental situation with respect to its significance for well-being (e.g., Bandura, 1997; Lazarus \& Folkman, 1984; LePine et al., 2004; LePine et al., 2005; Podsakoff et al., 2007). Primary appraisals assess the extent to which a situation is either comforting or stressfully demanding because existential needs for thermal comfort, nutrition, and health cannot be satisfactorily 
met. Secondary appraisals assess the extent to which a stressfully demanding situation is threatening or challenging given the available resources to meet the demands. Tertiary appraisals assess the extent to which various adaptations are functional in regard to satisfying existential needs in a comforting, threatening, or challenging situation.

Evolutionary psychologists (e.g., Buss, 1999; Tooby \& Cosmides, 1992) refer to outcomes of these appraisal processes as evoked culture-differences in human functioning explained by universal needs that are differentially expressed and satisfied across populations. Primary appraisals of demands evoke stress responses, secondary appraisals of resources evoke general motives, and tertiary appraisals of adaptations evoke specific ways of being and acting. As a spin-off of these widely accepted insights, climato-economic theorizing (Van de Vliert, 2009, 2013a, 2013b) proposes that primary appraisals of climatic demands, secondary appraisals of wealth resources, and tertiary appraisals of cultural adaptations shape human functioning.

Climatic demands. Primary appraisals assess the extent to which winters and summers are comforting or stressfully demanding given existential needs for thermal comfort, nutrition, and health; and also given that acclimatization through long-term adjustment in anatomy and physiology has negligible compensating effects (Parsons, 2003). These assessments are broadly relevant because unmet existential needs tend to proliferate into frustration of social needs and growth needs (Alderfer, 1972; Kenrick et al., 2010; Maslow, 1954). No matter how much focal attention processing is involved, temperate climates are almost always appraised as relatively comfortable. Colder winters and hotter summers are experienced as relatively stressful because they require more and better clothing, shelter structures, and heating or cooling systems, increasing investments of time and effort in the pursuit of foods and drinks, and more measures to safeguard family health.

Wealth resources. Secondary appraisals assess the extent to which stressfully demanding winters or summers are threatening or challenging given the available wealth resources (cash, capital, education, inspiring work, longevity) to meet the climatic demands. The seldom explicitly posed, yet implicitly answered, question is how well owning, buying, and inventing climate-compensating goods and services can help prevent and dispel discomfort, hunger, thirst, and illness by satisfying existential needs. All inhabitants of a certain area are exposed to the same winters, summers, and standard of living; are assessing and discussing this situation frequently; and are gradually pushing and pulling each other toward a predominantly shared appraisal of climato-economic livability. 
Poorer populations in climates with colder-than-temperate winters, hotter-thantemperate summers, or both are expected to appraise livability as stressful because the climatic demands are high and as threatening because the wealth resources to cope with the high stress are insufficient (threatening ecologies). Experienced stress is expected to be low in comforting temperate climates irrespective of income per head, because wealth resources do not make much difference for how well existential needs are satisfied in those climates (comforting ecologies). Richer populations in climates with colder-than-temperate winters, hotterthan-temperate summers, or both are expected to appraise livability as stressful because the climatic demands are high and as challenging because the wealth resources to cope with the high stress are sufficient (challenging ecologies).

The main idea is that greater climatic demands make wealth resources increasingly important for survival and a decent quality of life. In otherwise equal circumstances, cash and capital resources are least useful in comforting ecologies. But in colder-than-temperate or hotter-than-temperate conditions, wealth is an extraordinarily ingenious tool for turning threatening ecologies into challenging ecologies. This argument has been criticized because climate may help generate wealth (e.g., Ainslie, 2013). However, climatic demands do not plausibly account for collective wealth $(r=.37, n=175, p<.001$; Van de Vliert, 2011a). Even more important, conceptual boundaries are a basic requirement of any theory. It is thus a strength rather than a weakness to state that climatic demands and wealth resources influence each other's impact on daily life, and to not sidetrack into main effects of cold, heat, and wealth.

Cultural adaptations. Tertiary appraisals assess the extent to which the activation of certain goals, means, or outcomes helps or hinders livability in a threatening, comforting, or challenging ecology. For example, in essence discussing adaptations to threatening ecologies, Milgram (1974, pp. 123-124) convincingly argued that "the formation of hierarchically organized groupings lends enormous advantage to those so organized in coping with dangers of the physical environment." By striking contrast, the cultural syndrome of selfexpression in goals, means, and outcomes, which characterizes challenging ecologies (Van de Vliert, 2009), provides a "social force that operates in favor of democracy, helping to establish democracy where it does not yet exist, and strengthening democracy where it is already in place" (Inglehart \& Welzel, 2005, p. 299).

\section{Method: Measures and analyses}

Climatic demands. Annual mean temperature is an inadequate predictor of daily life because this indicator averages cold demands and heat demands, and overlooks seasonal variations in temperature. Nowadays, $22{ }^{\circ} \mathrm{C}$ (about $72{ }^{\circ} \mathrm{F}$ ) is adopted as a point of reference for optimal climatic livability because existential 
needs for thermal comfort, nutrition, and health are met more easily in temperate climates varying around a base range of, say, $17-27^{\circ} \mathrm{C}$. Climates are more demanding to the extent that seasons are colder than $22{ }^{\circ} \mathrm{C}$ or hotter than $22{ }^{\circ} \mathrm{C}$. Climatic demands are operationalized across each country's major cities, weighted for population size, as the sum of the absolute deviations from $22{ }^{\circ} \mathrm{C}$ for the average lowest and highest temperatures in the coldest month and in the hottest month (for details, see Van de Vliert, 2009, 2013a, 2013b).

Wealth resources. Income per head is measured with reference to the capacity of a country's currency to buy a given basket of basic goods and services (purchasing power parity in Geary-Khamis dollars, log transformed to reduce the skewed cross-national distribution).

Analyses. Seven characteristics of culture were regressed on standardized climatic demands, standardized wealth resources, and their climato-economic interaction, while controlling for variables representing rival explanations.

\section{Ecology of current cultures}

Ecological explanations of the origins of national cultures have been sought in annual mean temperature (Fought et al., 2004; Georgas et al., 2004; Vanhanen, 2009), parasitic-disease burden (Fincher \& Thornhill, 2012; Schaller \& Murray, 2011), voluntary settlement in frontier regions (Kitayama et al., 2010; Kitayama et al., 2006), and economic development (Inglehart \& Baker, 2000; Inglehart \& Welzel, 2005). Aiming to replace and go beyond such singlefactor explanations, climato-economic research has related national cultures to interactions of the negative climatic anchors of cold and heat and the positive economic anchors of cash and capital.

Following is a brief overview of the research results. The keyword summary in Figure 1 may serve as a reader's guide. Climato-economic ecologies are mapped out in the three rows at the top. The first row underneath the three arrows indicates that stresses in these ecologies are appraised as threatening, comforting, and challenging, respectively. Listed and italicized lower down in the column to the left are eight cultural characteristics crudely ordered from micro-level to meso-level to macro-level. The remaining keywords help interrelate and explain patterns of cultural manifestations in terms of threatening, comforting, and challenging climato-economic ecologies. To avoid false inferences of causality, these manifestations are called cultural covariations instead of cultural adaptations. 


\begin{tabular}{|c|c|c|c|}
\hline Thermal climate & Cold or hot & Temperate & Cold or hot \\
\hline Climatic demands & Demanding & Undemanding & Demanding \\
\hline Wealth resources & Poor & Poor or rich & Rich \\
\hline \multicolumn{4}{|l|}{ Cultural covariations } \\
\hline Ecological appraisal & Threatening & Comforting & Challenging \\
\hline Mental health & Ill-being & Mixed & Well-being \\
\hline Organizing & Bureaucratic & Mixed & Organic \\
\hline Outgroup treatment & Rejection & Mixed & Tolerance \\
\hline Media culture & Press repression & Mixed & Press freedom \\
\hline Political system & Autocratic & Mixed & Democratic \\
\hline Societal goals & Survival & Mixed & Self-expression \\
\hline Societal culture & Collectivism & Mixed & Individualism \\
\hline
\end{tabular}

Figure 1. Cultural covariations of threatening, comforting, and challenging combinations of climatic demands and wealth resources

\section{Mental health: III-being versus well-being}

Across 58 nations, climatic demands $(0 \%)$, wealth resources $(17 \%)$, and their climato-economic interaction $(21 \%)$ accounted for $38 \%$ of the variation in mental health (Fischer \& Van de Vliert, 2011). Anxiety, depression, burnout, and perceived ill health appeared to be most prevalent in poor populations residing in climates with more-demanding winters or summers (e.g., Iranians and Serbs), intermediately prevalent in populations residing in undemanding temperate climates irrespective of income per head (e.g., Hong Kongers and Sri Lankans), and least prevalent in rich populations residing in climates with more-demanding winters or summers (e.g., Finns and Swiss). The observed prevalences of mental ill-being in threatening ecologies but mental well-being in challenging ecologies, both contrasting with more of a mix of ill-being and well-being in comforting ecologies, form a first confirmation of the storyline in Figure 1. 


\section{Organizing: Bureaucratic versus organic}

Across 58 nations, climatic demands (5\%), wealth resources $(21 \%)$, and their interaction $(11 \%)$ predicted $37 \%$ of the country-level differences in how organizations are structured (Van de Vliert, 2009). Food-processing organizations, financial-service organizations, and telecommunication-service organizations are bureaucratically structured using relatively large degrees of formalization and centralization in threatening ecologies (e.g., China and Poland). By contrast, these organizations are made relatively organic with little formalization and centralization in challenging ecologies (e.g., Germany and Sweden). More of a structural mix is observed in comforting ecologies (e.g., Colombia and Japan). An interesting yet speculative implication here is that if we were to compare the bureaucratic templates of all McDonald's fast-food restaurants around the globe, we would find thousands of small adaptations in challenging and comforting ecologies. Does even the McDonaldization of the world (Ritzer, 2004) have to obey the rules of climato-economics?

\section{Outgroup treatment: Rejection versus tolerance}

Across 85 nations, climatic demands (2\%), wealth resources (35\%), and their climato-economic interaction (5\%) accounted for $42 \%$ of the extent to which randomly sampled citizens tend to reject rather than tolerate members of outgroups including people of a different race, immigrants/foreign workers, and homosexuals (Van de Vliert, 2013a). A visual plot of the results leads to the conclusion that rejection of outgroup members is strongest among populations in threatening ecologies (e.g., Bosnians and Turks), moderately strong among populations in comforting ecologies (e.g., Maltese and Peruvians), and weakest among populations in challenging ecologies (e.g., Dutch and Icelanders). Apparently, there is a real-life connection between harsher environments and harsher treatment of categories of people whom we don't want to link up with.

\section{Media culture: Press repression versus press freedom}

Across 175 nations, climatic demands $(0 \%)$, wealth resources $(31 \%)$, and their interaction $(8 \%)$ predicted $39 \%$ of the uneven worldwide distribution of press repression (Van de Vliert, 2011a). The specifics and particulars of this finding are very robust, holding up for each of three subsequent years, and for separate indices constructed by Freedom House (perpetrator perspective), World Economic Forum (relational perpetrator-victim perspective), and Reporters Without Borders (victim perspective). Nine tests consistently revealed that journalists and media assistants are bullied most in threatening ecologies 
(e.g., Sudan and Uzbekistan), to a moderate extent in countries where citizens are comforted by undemanding climates (e.g., Honduras and Seychelles), and least in challenging ecologies (e.g., Denmark and Switzerland).

\section{Political system: Autocratic versus democratic}

Across 174 nations, climatic demands (6\%), wealth resources (22\%), and climate and wealth in concert (7\%) accounted for $35 \%$ of the systemic differences in political governance (Van de Vliert \& Postmes, 2012). Our visualization of the effects illustrated that autocratic systems thrive among inhabitants of threatening habitats (e.g., Afghans and Swazis), that democratic systems thrive among inhabitants of challenging habitats (e.g., North Americans and Czechs), and that neither of them has priority among inhabitants of comforting habitats (e.g., Bahamians and Sierra Leoneans). More detailed analyses (Van de Vliert, 2013 b) showed that autocratic systems peak in poor populations coping with both cold winters and hot summers, and that democratic systems peak in rich populations coping with cold winters and temperate summers.

\section{Societal goals: Survival versus self-expression}

Across 77 nations, climatic demands $(0 \%)$, wealth resources $(52 \%)$, and their interaction $(20 \%)$ accounted for $72 \%$ of the variation in the World Values Surveys dimension of survival versus self-expression (Van de Vliert, 2009). As predicted, survival goals prevail in poorer populations threatened by moredemanding thermal climates (e.g., Armenians and Latvians), self-expression goals prevail in richer populations challenged by more-demanding thermal climates (e.g., Canadians and Finns), and more easygoing goals prevail in populations comforted by undemanding climates irrespective of their wealth (e.g., Ghanaians and Singaporeans). As a noteworthy consequence, during 8- to 19-year periods, populations in more threatening ecologies moved away from self-expression goals toward survival goals to the extent that they were exposed to economic decline.

\section{Societal culture: Collectivism versus individualism}

Across 121 nations, climatic demands (4\%), wealth resources (33\%), and the interaction of these climatic and economic factors (10\%) predicted $47 \%$ of the variance in a composite index of favoritism shown to one's own relatives and the larger family of locals (Van de Vliert \& Postmes, 2012). Societal collectivism is strongest in the threatening ecologies of lower-income countries with moredemanding thermal climates (e.g., Tajiks and Mongolians), moderate in the comforting ecologies of countries with undemanding temperate climates (e.g., Barbadians and Beninians), and weakest in the challenging ecologies of 
higher-income countries with more-demanding thermal climates (e.g., North Americans and Scandinavians). Perhaps it should not come as a surprise that these results reflect the results for outgroup treatment because cultural collectivism, characterized by ingroup favoritism, tends to move in tandem with outgroup rejection.

\section{Ecology of we/they discrimination}

Ingroup love and outgroup hate are indeed flip sides of the same coin, both referring to one of the world's most vexing problems: large-scale discrimination between people. Not only are we and us unthinkable without the existence of they and them, but stronger positive discrimination of one's own group inside an intergroup boundary also tends to go hand in hand with negative discrimination of at least one other group outside that boundary. Conversely, a given extent of discriminatory outgroup hate tends to elicit a similar extent of discriminatory ingroup love. In consequence, it is hard to tell one from the other, let alone tell which one comes first and causes the other (for causality, see Brewer, 1999; Halevy et al., 2012; Van de Vliert, 2013a). Therefore, this section reports a unique first attempt to integrate indices of ingroup love and outgroup hate into an index of we/they discrimination, and to scrutinize the degrees of discrimination between groups in relation to the ecologies visualized in Figure 1.

\section{Theoretical framework}

Applied to intergroup relations, climato-economic theorizing (Van de Vliert, 2009, 2013a, 2013b) proposes that we/they discrimination is shaped by (a) primary appraisals of winter and summer demands in terms of how stressful it is to meet existential needs for thermal comfort, nutrition, and health; (b) secondary appraisals of how threatening or challenging stressful winters and summers are given the available wealth resources to meet the climatic demands; and (c) tertiary appraisals of how helpful or harmful we/they discrimination is for dealing with the threatening, comforting, or challenging ecology. Relatively strong we/they discrimination is expected to predominate in threatening ecologies, where it is consistent with bureaucratic organizing, press repression, autocratic politics, and survival goals. By contrast, relatively weak we/they discrimination is expected to predominate in challenging ecologies, where it is consistent with organic organizing, press freedom, democratic politics, and self-expression goals. In between, comforting ecologies are expected to be characterized by moderately strong degrees of we/they discrimination. These expectations were tested in a secondary analysis of cross-national data. 


\section{Sampling}

Countries. Ninety-five nations from all inhabited continents were included, for which sufficient data on we/they discrimination were publicly available for analysis (for details, see Table 1). From a worldwide viewpoint, there was an underrepresentation of countries with undemanding climates $(t=5.24$, $p<.001)$ and poorer economic resources $(t=3.97, p<.001)$, which ensured a conservative test of the climato-economic model.

Respondents. International bodies, mentioned below, used nationally representative sampling methods to recruit over 200,000 participants who answered questions about either positive ingroup discrimination $(N=133,163)$ or negative outgroup discrimination $(N>95,000)$.

\section{Dependent variable}

We/they discrimination was measured with three indicators of positive discrimination of insiders (familism, nepotism, compatriotism) and five indicators of negative discrimination of outsiders (different races, foreigners, homosexuals, AIDS patients, criminals).

Familism. Survey participants in 57 countries $(N=17,370)$ were asked about the advantageous treatment of one's closest relatives in the form of mutually beneficial exchanges of housing benefits and pride between parents and children ( 1 = strongly disagree, 7 = strongly agree; source: House et al., 2004; for intraclass correlation, internal consistency, interrater reliability, and construct validity, see Van de Vliert, 2011b).

Nepotism. Top executives in 94 countries $(N=10,932)$ responded to the item, "Senior management positions in your country are usually held by ... [1] professional managers chosen based on superior qualification ... [7] relatives" (source: World Economic Forum, 2005; for intraclass correlation, test-retest reliability, and construct validity, see Van de Vliert, 2011b).

Compatriotism. In the 1999-2002 wave of the World Values Surveys covering 74 countries (sources: www.worldvaluessurvey.org; Inglehart et al., 2004), interviewers of 104,861 interviewees were instructed to substitute their own nationality for "British" when asking, "Do you agree or not agree with the following statement? When jobs are scarce, employers should give priority to [British] people over immigrants" (agree, disagree, neither; for interrater reliability and criterion validity, see Van de Vliert, 2011b).

Negative outgroup discrimination. Discrimination of outsiders was derived from the fourth and fifth waves of the World Values Surveys (sources: www.worldvaluessurvey.org; Inglehart et al., 2004). In face-to-face 
interviews covering 95 countries, at least 1,000 adults per country were asked, "On this list are various groups of people. Could you please sort out any that you would not like to have as neighbors? ... People of a different race ... Immigrants/foreign workers ... Homosexuals ... People who have AIDS ... People with a criminal record" ( $0=$ not mentioned, $1=$ mentioned $)$. These five internally consistent indicators (Cronbach's $\alpha=.79$ ) were standardized and then averaged to represent negative outgroup discrimination.

Overall index. The above country-level estimates of familism, nepotism, compatriotism, and negative outgroup discrimination were standardized and then averaged into an overarching index of the degree of we/they discrimination $\left(R^{2}=.77 ;\right.$ Cronbach's $\left.\alpha=.90\right)$.

\section{Predictors}

Independent variable: climatic demands. The sum of the absolute deviations from $22{ }^{\circ} \mathrm{C}$ for the average lowest and highest temperatures in the coldest month and in the hottest month (source: Van de Vliert, 2009).

Independent variable: wealth resources. The natural logarithm of the purchasing power product per capita in 2002 (source: UNDP, 2004).

Control variable: land borders. Unlike islanders, inhabitants of landlocked areas are physically surrounded by outgroups from neighboring countries, with the potential consequence that national borders are more strongly turned into social boundaries and we/they discrimination. To test this rival explanation, I controlled for the extent to which a country is sharing land borders rather than sea borders with other countries $(1=$ island; $2=$ borders $<$ coastlines; 3 = borders $>$ coastlines; 4 = landlocked; source: Parker, 1997).

Control variable: parasitic diseases. According to the parasite-stress theory (Fincher \& Thornhill, 2012; Fincher et al., 2008), boundaries between ingroups and outgroups will be emphasized more and guarded better in regions where it is more likely that outgroup members transmit infectious diseases to ingroup members Therefore, the prevalence of nonzoonotic parasitic diseases (source: Fincher \& Thornhill, 2012) as a potential confounding determinant of we/they discrimination was also taken into account.

Control variable: natural disasters. Another competing explanation is that environments also differ in the occurrence of natural disasters, and that disaster threats may co-occur with climato-economic threats. This potential validity problem I addressed by controlling for the national logarithm of the average part of the population affected by earthquakes, volcanic eruptions, droughts, wildfires, floods, storms, and the like, during the first decade of this century (source: UNDP, 2010). 
Human Ecology Review, Volume 21, Number 2, 2015

Table 1. Scores, means, and standard deviations of dependent, independent, and control variables for 95 nations

\begin{tabular}{|c|c|c|c|c|c|c|}
\hline Countries & $\begin{array}{c}\text { We/they } \\
\text { discrimination }\end{array}$ & $\begin{array}{l}\text { Climatic } \\
\text { demands }\end{array}$ & $\begin{array}{l}\text { Wealth } \\
\text { resources }\end{array}$ & $\begin{array}{c}\text { Geographic } \\
\text { borders }\end{array}$ & $\begin{array}{l}\text { Parasitic } \\
\text { diseases }\end{array}$ & $\begin{array}{c}\begin{array}{c}\text { Natural } \\
\text { disasters }\end{array} \\
\end{array}$ \\
\hline Albania & .82 & 62 & 8.48 & 3 & -1.88 & 9.97 \\
\hline Algeria & .84 & 55 & 8.66 & 3 & 1.26 & 6.43 \\
\hline Argentina & -.25 & 65 & 9.29 & 3 & 1.26 & 7.58 \\
\hline Armenia & .79 & 89 & 8.05 & 4 & -1.28 & 9.28 \\
\hline Australia & -1.43 & 76 & 10.25 & 1 & -1.12 & 6.13 \\
\hline Austria & -.71 & 83 & 10.28 & 4 & -1.72 & 6.71 \\
\hline Azerbaijan & 1.19 & 89 & 8.07 & 4 & -1.13 & 6.16 \\
\hline Bangladesh & .82 & 44 & 7.44 & 3 & .07 & 10.81 \\
\hline Belgium & -1.02 & 79 & 10.22 & 3 & -1.73 & 3.33 \\
\hline Bolivia & 1.13 & 51 & 7.81 & 4 & 1.85 & 9.79 \\
\hline $\begin{array}{l}\text { Bosnia and } \\
\text { Herzegovina }\end{array}$ & -.45 & 80 & 8.69 & 4 & -1.74 & 9.29 \\
\hline Brazil & -.15 & 43 & 8.96 & 3 & 3.95 & 8.27 \\
\hline Bulgaria & .94 & 78 & 8.87 & 3 & -1.44 & 5.32 \\
\hline Canada & -1.39 & 105 & 10.29 & 2 & -1.87 & 4.16 \\
\hline Chile & -.27 & 62 & 9.19 & 2 & -.08 & 8.47 \\
\hline China & .58 & 82 & 8.43 & 3 & 1.85 & 11.15 \\
\hline Colombia & -.26 & 35 & 8.76 & 3 & 3.97 & 9.33 \\
\hline Costa Rica & .09 & 39 & 9.09 & 2 & 1.55 & 9.34 \\
\hline Croatia & .59 & 83 & 9.23 & 3 & -1.59 & 3.97 \\
\hline Cyprus & .56 & 57 & 9.81 & 1 & -1.73 & .00 \\
\hline Czech Republic & -.18 & 91 & 9.67 & 4 & -1.88 & 7.76 \\
\hline Denmark & -1.80 & 83 & 10.34 & 2 & -1.87 & .00 \\
\hline Dominican Republic & .02 & 35 & 8.80 & 2 & .53 & 8.11 \\
\hline Ecuador & .89 & 52 & 8.18 & 2 & 2.00 & 9.12 \\
\hline Egypt & .54 & 60 & 8.25 & 3 & .81 & 1.10 \\
\hline El Salvador & .69 & 55 & 8.49 & 3 & .21 & 10.60 \\
\hline Estonia & -.66 & 98 & 9.41 & 2 & -1.58 & 2.20 \\
\hline Ethiopia & .50 & 54 & 6.66 & 3 & 3.81 & 10.53 \\
\hline Finland & -1.10 & 98 & 10.17 & 3 & -2.02 & 2.20 \\
\hline France & -1.11 & 75 & 10.20 & 3 & -1.13 & 4.69 \\
\hline Georgia & .70 & 65 & 7.72 & 3 & -.98 & 9.85 \\
\hline Germany & -1.28 & 84 & 10.21 & 3 & -2.02 & 6.11 \\
\hline Ghana & .09 & 34 & 7.66 & 3 & 3.24 & 8.08 \\
\hline Greece & .04 & 56 & 9.84 & 2 & -.99 & 5.28 \\
\hline
\end{tabular}


Current Cultures in Threatening, Comforting, and Challenging Ecologies

\begin{tabular}{|c|c|c|c|c|c|c|}
\hline Countries & $\begin{array}{c}\text { We/they } \\
\text { discrimination }\end{array}$ & $\begin{array}{l}\text { Climatic } \\
\text { demands }\end{array}$ & $\begin{array}{c}\text { Wealth } \\
\text { resources }\end{array}$ & $\begin{array}{c}\text { Geographic } \\
\text { borders }\end{array}$ & $\begin{array}{l}\text { Parasitic } \\
\text { diseases }\end{array}$ & $\begin{array}{c}\text { Natural } \\
\text { disasters }\end{array}$ \\
\hline Guatemala & .42 & 43 & 8.31 & 3 & 1.71 & 10.21 \\
\hline Hong Kong & .83 & 40 & 10.20 & 2 & -1.26 & 4.43 \\
\hline Hungary & .39 & 84 & 9.50 & 4 & -1.89 & 6.23 \\
\hline Iceland & -1.07 & 73 & 10.30 & 1 & -1.87 & 3.81 \\
\hline India & .39 & 53 & 7.89 & 3 & 2.16 & 10.93 \\
\hline Indonesia & .71 & 30 & 8.08 & 2 & 3.35 & 8.50 \\
\hline Ireland & -.53 & 69 & 10.50 & 2 & -1.87 & 3.85 \\
\hline Israel & -.69 & 59 & 9.88 & 3 & -1.59 & 2.30 \\
\hline Italy & -.12 & 59 & 10.18 & 2 & -1.43 & 4.85 \\
\hline Japan & -.59 & 52 & 10.20 & 1 & -.85 & 7.23 \\
\hline Jordan & 1.30 & 60 & 8.35 & 3 & -.69 & 7.88 \\
\hline Kazakhstan & .64 & 104 & 8.68 & 4 & -1.59 & 6.35 \\
\hline Kuwait & .78 & 55 & 9.70 & 2 & -1.14 & .00 \\
\hline Latvia & -.21 & 98 & 9.13 & 3 & -1.73 & 1.79 \\
\hline Lithuania & .44 & 98 & 9.24 & 3 & -1.73 & .00 \\
\hline Luxembourg & -1.30 & 85 & 11.02 & 4 & -2.02 & .00 \\
\hline Macedonia & .75 & 80 & 8.77 & 4 & -1.74 & 11.01 \\
\hline Malawi & .67 & 50 & 6.36 & 4 & 2.03 & 11.16 \\
\hline Malaysia & -.25 & 33 & 9.12 & 3 & 1.85 & 7.42 \\
\hline Mali & .83 & 56 & 6.84 & 4 & 3.82 & 9.16 \\
\hline Malta & .59 & 39 & 9.78 & 1 & -1.69 & \\
\hline Mexico & .37 & 49 & 9.10 & 2 & 2.31 & 8.79 \\
\hline Moldova & .27 & 87 & 7.29 & 4 & -1.43 & 11.37 \\
\hline Montenegro & .62 & 83 & 8.76 & 3 & -1.44 & 5.61 \\
\hline Morocco & 1.29 & 63 & 8.25 & 3 & .07 & 7.05 \\
\hline Namibia & -.53 & 56 & 8.73 & 3 & 1.12 & 10.66 \\
\hline Netherlands & -1.86 & 77 & 10.28 & 3 & -1.87 & .00 \\
\hline New Zealand & -1.60 & 53 & 9.99 & 1 & -1.87 & 5.25 \\
\hline Nigeria & .52 & 37 & 6.76 & 3 & 4.73 & 6.07 \\
\hline Norway & -1.49 & 89 & 10.51 & 2 & -1.87 & 3.91 \\
\hline Pakistan & -.36 & 59 & 7.57 & 3 & .82 & 9.10 \\
\hline Peru & -.11 & 35 & 8.52 & 3 & 2.30 & 9.80 \\
\hline Philippines & .57 & 36 & 8.34 & 1 & 1.55 & 11.00 \\
\hline Poland & .49 & 90 & 9.26 & 3 & -1.73 & 4.13 \\
\hline Portugal & -.27 & 51 & 9.81 & 2 & -1.14 & 7.35 \\
\hline Qatar & .01 & 53 & 9.90 & 2 & -.97 & \\
\hline Romania & .32 & 93 & 8.79 & 3 & -1.13 & 6.98 \\
\hline
\end{tabular}




\begin{tabular}{|l|c|c|c|c|c|c|}
\hline Countries & $\begin{array}{c}\text { We/they } \\
\text { discrimination }\end{array}$ & $\begin{array}{c}\text { Climatic } \\
\text { demands }\end{array}$ & $\begin{array}{c}\text { Wealth } \\
\text { resources }\end{array}$ & $\begin{array}{c}\text { Geographic } \\
\text { borders }\end{array}$ & $\begin{array}{c}\text { Parasitic } \\
\text { diseases }\end{array}$ & $\begin{array}{c}\text { Natural } \\
\text { disasters }\end{array}$ \\
\hline Russia & .36 & 101 & 9.02 & 2 & .52 & 7.33 \\
\hline Serbia & .62 & 83 & 8.76 & 4 & -1.44 & 5.18 \\
\hline Singapore & -.16 & 29 & 10.09 & 2 & -.85 & 3.97 \\
\hline Slovakia & .32 & 96 & 9.46 & 4 & -2.03 & 5.39 \\
\hline Slovenia & .04 & 83 & 9.83 & 3 & -1.59 & 3.53 \\
\hline South Africa & -.36 & 63 & 9.22 & 3 & 1.41 & 10.43 \\
\hline South Korea & .79 & 79 & 9.74 & 2 & .21 & 7.12 \\
\hline Spain & -.54 & 69 & 9.97 & 2 & -.99 & 3.04 \\
\hline Sweden & -2.17 & 89 & 10.17 & 3 & -1.72 & 1.61 \\
\hline Switzerland & -1.23 & 83 & 10.31 & 4 & -1.72 & 4.69 \\
\hline Taiwan & .33 & 49 & 10.06 & 1 & -.54 & \\
\hline Tanzania & .05 & 43 & 6.36 & 3 & 2.92 & 9.50 \\
\hline Thailand & .36 & 45 & 8.86 & 3 & 2.59 & 10.74 \\
\hline Trinidad and Tobago & -.49 & 46 & 9.15 & 1 & -.07 & 4.99 \\
\hline Turkey & .69 & 85 & 8.76 & 2 & .06 & 6.86 \\
\hline Uganda & .58 & 38 & 7.24 & 4 & 4.41 & 9.30 \\
\hline Ukraine & .29 & 87 & 8.49 & 3 & -.98 & 7.35 \\
\hline United Kingdom & -1.23 & 67 & 10.17 & 2 & -2.02 & 6.53 \\
\hline United States & -1.36 & 79 & 10.48 & 2 & -.69 & 8.90 \\
\hline Uruguay & .16 & 65 & 8.97 & 3 & -1.28 & 8.48 \\
\hline Venezuela & .30 & 42 & 8.59 & 3 & 3.22 & 6.23 \\
\hline Vietnam & .41 & 48 & 7.74 & 3 & 1.98 & 10.15 \\
\hline Zambia & .70 & 48 & 6.73 & 4 & 2.48 & 11.06 \\
\hline Zimbabwe & .07 & 52 & 7.77 & 4 & 1.43 & 11.23 \\
\hline Mean & .01 & 65.23 & 9.00 & 2.76 & -.07 & 6.73 \\
\hline Standard deviation & .79 & 20.40 & 1.08 & .88 & 1.91 & 3.20 \\
\hline
\end{tabular}

\section{Results and discussion}

Descriptives. Country scores, mean scores, and standard deviations of the study variables are provided in Table 1. The zero-order correlations in Table 2 show that we/they discrimination is weaker among populations residing in more-demanding climates $(r=-.26, p<.01)$, and in poorer countries $(r=-.65$, $p<.001)$; and stronger among populations residing in more enclosed countries $(r=.24, p<.05)$, and in areas with a larger parasitic-disease burden $(r=.36$, $p<.001)$ or natural-disaster burden $(r=.42, p<.001)$. An additional finding is that climatic demands have a negligible association with we/they discrimination 
$(r=-.05, n s)$ after controlling for wealth resources. This is a theoretically important observation as it moves us away from the myopic single-factor explanation of culture offered by proponents of climatic determinism (e.g., Huntington, 1945; Taylor, 1937; Vanhanen, 2009).

Table 2. Intercorrelations of dependent, independent, and control variables across 95 nations

\begin{tabular}{|l|c|c|c|c|c|}
\hline Variable & $\mathbf{1}$ & $\mathbf{2}$ & $\mathbf{3}$ & $\mathbf{4}$ & $\mathbf{5}$ \\
\hline 1. We/they discrimination & & & & & \\
\hline 2. Climatic demands & $-.26^{\star \star}$ & & & & \\
\hline 3. Wealth resources & $-.65^{\star \star \star}$ & $.34^{\star \star \star}$ & & & \\
\hline 4. Geographic borders & $.24^{\star}$ & $.26^{\star \star}$ & $-.44^{\star \star \star}$ & & \\
\hline 5. Parasitic diseases & $.36^{\star \star \star}$ & $-.67^{\star \star \star}$ & $-.67^{\star \star \star}$ & .12 & \\
\hline 6. Natural disasters & $.42^{\star \star \star}$ & $-.41^{\star \star \star}$ & $-.64^{\star \star \star}$ & $.25^{\star \star}$ & $.57^{\star \star \star}$ \\
\hline
\end{tabular}

Note. Scores are missing for natural disasters in Malta, Qatar, and Taiwan $(N=92)$.

${ }^{\star} p<.05 .{ }^{\star \star} p<.01 .{ }^{\star \star \star} p<.001$.

Extension of the storyline. The first three regression models in Table 3 show that climatic demands $(7 \%)$, wealth resources $(35 \%)$, and their climato-economic interaction ( $15 \%$ ) accounted for $57 \%$ of the cross-national variation in we/they discrimination. The fourth model reveals that land borders, parasitic diseases, and natural disasters predicted $24 \%$ of the differences in discrimination. However, when the two sets of predictors were combined, land borders, parasitic diseases, and natural disasters could not additionally account for any variation in we/ they discrimination over and above the climato-economic influence (see last model in Table 3).

Table 3. Climatic demands, wealth resources, and control variables predicting we/they discrimination

\begin{tabular}{|c|c|c|c|c|c|}
\hline Predictor & $B$ & $B$ & $B$ & $B$ & $B$ \\
\hline Land borders & & & & $.18^{\star}$ & .04 \\
\hline Parasitic diseases & & & & .08 & .01 \\
\hline Natural disasters & & & & $.07^{\star}$ & -.02 \\
\hline Climatic demands (CD) & $-.23^{\star \star}$ & -.04 & $.14^{\star}$ & & .14 \\
\hline Wealth resources (WR) & & $-.53^{\star \star \star}$ & $-.37^{\star \star \star}$ & & $-.40^{\star \star \star}$ \\
\hline$C D \times W R$ & & & $-.42^{\star \star \star}$ & & $-.42^{\star * \star}$ \\
\hline$\Delta R^{2}$ & $.07^{\star \star}$ & $.35^{\star \star \star}$ & $.15^{\star \star \star}$ & $.24^{\star \star \star}$ & $.34^{\star \star \star}$ \\
\hline Total $R^{2}$ & $.07^{\star \star}$ & $.42^{\star \star \star}$ & $.57^{\star \star \star}$ & $.24^{\star \star \star}$ & $.58^{\star \star \star}$ \\
\hline
\end{tabular}

Note. $N=95$ in the first three prediction models. $N=92$ in the last two models. There was no multicollinearity (VIFs < 3.81) and there were no outliers (Cook's $D s<.19$ ).

${ }^{*} p<.05 .{ }^{* *} p<.01 .{ }^{* \star *} p<.001$. 
Figure 2 visualizes the details of the regression results. The upper slope indicates that populations in more-demanding climates tend to discriminate more in favor of ingroups and against outgroups if they are poor $(B=.57$, $p<.001)$. The lower slope indicates that populations in more-demanding climates tend to discriminate less in favor of ingroups and against outgroups if they are $\operatorname{rich}(B=-.28, p<.001)$. When the two slopes are read and interpreted together, they extend the overall storyline in Figure 1: we/they discrimination is most prevalent in poor populations residing in more-demanding climates (e.g., Azerbaijanis and Montenegrins), intermediately prevalent in populations residing in undemanding temperate climates irrespective of income per head (e.g., Indonesians and Singaporeans), and least prevalent in rich populations residing in more-demanding climates (e.g., Australians and Luxembourgers).

- - $\mathbf{A}$ - - Poor countries

- - - Rich countries

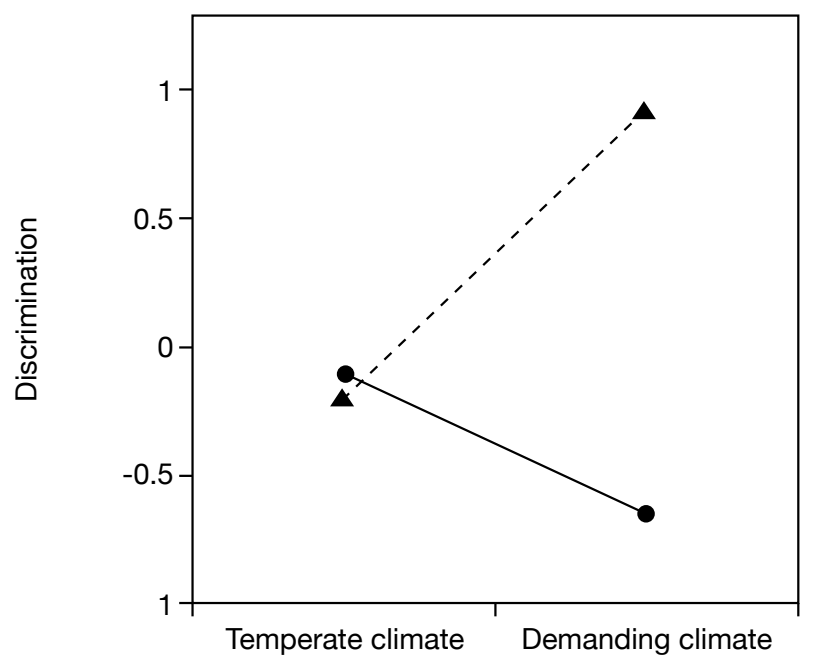

Figure 2. Interactive effects of climatic demands and wealth resources on we/they discrimination in 95 poorer and richer countries

The extended storyline of the ecology of national cultures implies that economic prosperity does not necessarily propel human functioning in the direction of less centralization, formalization and discrimination, and more individualization, as the World Values group would have it (e.g., Inglehart \& Baker, 2000; Inglehart \& Welzel, 2005; Welzel, 2013). Populations in undemanding temperate climates are relatively insensitive to the level of national wealth when making decisions about achieving goals by means of oneself or members of ingroups or outgroups. Only populations in more-demanding climates seem to propel away from 
bureaucratization and we/they discrimination toward self-expression and social equality when they get richer. This may be an especially important point for the Human Development Programme of the United Nations because positive ingroup discrimination and negative outgroup discrimination often go hand in hand with unintended re-routing of money streams and redistribution of rights and duties.

Self-evidently, climato-economic theorizing provides a partial explanation of we/ they discrimination at best. For a number of countries studied, ethnic diversity, social upheaval, and illegal or unwanted immigration also play important roles in shaping ingroup love and outgroup hate. Nevertheless, the reported accumulating results make it increasingly difficult to escape the impression that cultures are also shaped differently in threatening, comforting, and challenging ecologies (but see Ainslie, 2013; Arantes et al., 2013; Chang et al., 2013; Murray, 2013). We should keep in mind, however, that the climato-economic paradigm is no exception to the rule that each theory has a domain where it does apply, a domain where it may or may not apply, and a domain where it does not apply at all (for details, see Van de Vliert, 2013b). The upshot of the present study is that we/they discrimination seems to belong to the domain where climato-economic theorizing does apply.

Refinement of the storyline. Obviously, the bipolar structure of colder-thantemperate and hotter-than-temperate climates is not necessarily symmetrical. On the contrary, it is unlikely that climatic demands, measured in degrees Celsius as absolute deviations from $22{ }^{\circ} \mathrm{C}$, are approximately the same on the cold side and the hot side. De Oliveira Chen and Kitayama (2013) rightly observe that winters on this planet are generally more problematic than summers, with the consequence that cultures are shaped by winters rather than summers. Winter demands range from an absolute deviation of 1 on the Marshall Islands to a relatively high peak of 87 in Mongolia, whereas summer demands range from 2 in Colombia to a relatively low peak of 44 in Sudan (Van de Vliert, 2009). The smaller range of summer demands is caused by more direct and more concentrated sun rays, as well as more sun exposure because of the many daylight hours in summer.

In order to map the differential effect of winters and summers, the above analysis was refined using cold demands and heat demands (source: Van de Vliert, $2013 \mathrm{~b}$ ) as separate conditions that influence the impact of wealth resources on we/they discrimination. The results in Table 4 reveal that heat demands do not play a significant part in predicting discrimination. Nonetheless, as illustrated by the two upper slopes in Figure 3, greater cold in poor countries has a more convincing positive effect on discrimination if heat demands are low (upper left slope: $B=.67, p<.001$ ) rather than high (upper right slope: $B=.42, n s$ ). Consistently, as illustrated by the two lower slopes in Figure 3, greater cold 
in rich countries has a more convincing negative effect on discrimination if heat demands are low (lower left slope: $B=-.23, p<.05$ ) rather than high (lower right slope: $B=-.19, n s$ ). Continuing global warming may influence these effects, making the right-hand picture in Figure 3 at least as pronounced as the comparable left-hand picture.

Table 4. Cold demands, heat demands, and wealth resources predicting we/they discrimination

\begin{tabular}{|c|c|c|c|c|c|}
\hline Predictor & $B$ & $B$ & $B$ & $B$ & $B$ \\
\hline Cold demands (CoD) & -.14 & -.06 & .07 & $.18^{\star}$ & .17 \\
\hline Heat demands (HeD) & .20 & .19 & .11 & .14 & .12 \\
\hline $\mathrm{CoD} \times \mathrm{HeD}$ & & .16 & .14 & -.01 & -.05 \\
\hline Wealth resources (WR) & & & $-.50^{\star \star \star}$ & $-.34^{\star \star \star}$ & $-.31^{\text {***}}$ \\
\hline $\mathrm{CoD} \times \mathrm{WR}$ & & & & $-.41^{\star \star \star}$ & $-.38^{* * *}$ \\
\hline $\mathrm{HeD} \times W R$ & & & & -.00 & -.00 \\
\hline $\mathrm{CoD} \times \mathrm{HeD} \times \mathrm{WR}$ & & & & & .07 \\
\hline$\Delta R^{2}$ & $.14^{\star \star \star}$ & .02 & $.29^{\star \star \star}$ & $.14^{\star \star \star}$ & .00 \\
\hline Total $R^{2}$ & $.14^{\star \star \star}$ & $.16^{\star \star \star}$ & $.45^{\star \star \star}$ & $.59^{\star \star \star}$ & $.59^{\star \star \star}$ \\
\hline
\end{tabular}

Note. $N=95$ in all prediction models. There was no multicollinearity (VIFs $<4.51)$ and there were no outliers (Cook's Ds <.46).

${ }^{\star} p<.05 .{ }^{* \star} p<.01 .{ }^{* \star} p<.001$.
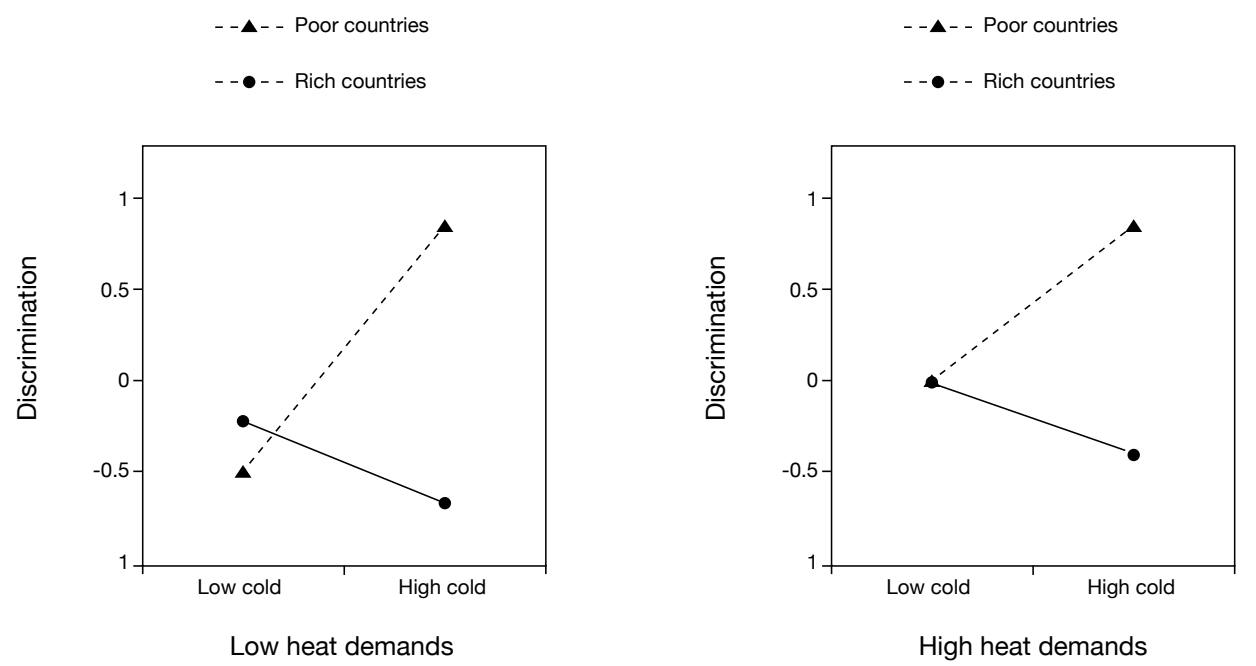

Figure 3. Interactive effects of cold demands, heat demands, and wealth resources on we/they discrimination in 95 poorer and richer countries 


\section{Concluding perspective}

Taken together, the results of the present and prior research suggest that mutually entwined ingroup love and outgroup hate, and other aspects of national culture (listed in Figure 1) are shaped differently in threatening, comforting, and challenging places of residence. Poorer populations in climates with colderthan-temperate winters, hotter-than-temperate summers, or both (threatening ecologies) are prone to relatively strong we/they discrimination, mental ill-being, bureaucratic organizing, press repression, autocratic politics, and survival goals. Richer populations in climates with colder-than-temperate winters, hotter-thantemperate summers, or both (challenging ecologies) are prone to relatively weak we/they discrimination, mental well-being, organic organizing, press freedom, democratic politics, and self-expression goals. Comforting ecologies in between these extremes tend to be home to intermediate cultural realities.

Although this article perhaps raises more problems than it answers, especially about the natural way in which our species has developed throughout history to ultimately create the cultures that we know today, it does make a point. The climato-economic covariations of culture reviewed here seem to render it impossible to sketch a convincing picture of present-day creation of culture if we continue to neglect or underemphasize the crucially important part played by the interaction of winter demands, summer demands, and wealth resources to meet these climatic demands. A good deal of the still unsolved ecology-ofculture puzzles can be summarized in the following question for further research: In what domains, in what ways, and to what extent have cultural adaptations in humans contrived to integrate climatic and economic underpinnings?

\section{Acknowledgments}

For helpful suggestions and critical comments on draft versions of this article, I thank Huadong Yang and two anonymous reviewers of this journal.

\section{References}

Ainslie, G. (2013). Cold climates demand more intertemporal self-control than warm climates. Behavioral and Brain Sciences, 36, 481-482.

Alderfer, C. P. (1972). Existence, relatedness, and growth: Human needs in organizational settings. New York: Free Press.

Arantes, J., Grace, R. C., \& Kemp, S. (2013). Press freedom, oil exports, and risk for natural disasters: A challenge for climato-economic theory? Behavioral and Brain Sciences, 36, 483. 
Bandura, A. (1997). Self-efficacy: The exercise of control. New York: Freeman.

Brewer, M. B. (1999). The psychology of prejudice: Ingroup love or outgroup hate? Journal of Social Issues, 55, 429-444.

Buss, D. M. (1999). Evolutionary psychology: The new science of the mind. Boston, MA: Allyn and Bacon.

Chang, L., Chen, B. B., \& Lu, H. J. (2013). Cultural adaptation to environmental change versus stability. Behavioral and Brain Sciences, 36, 485-486.

de Oliveira Chen, S., \& Kitayama, S. (2013). Frontier migration fosters ethos of independence: Deconstructing the climato-economic theory of human culture. Behavioral and Brain Sciences, 36, 486-487.

Fincher, C. L., \& Thornhill, R. (2012). Parasite-stress promotes in-group assortative sociality: The cases of strong family ties and heightened religiosity. Behavioral and Brain Sciences, 35, 61-79.

Fincher, C. L., Thornhill, R., Murray, D. R., \& Schaller, M. (2008). Pathogen prevalence predicts human cross-cultural variability in individualism/ collectivism. Proceedings of the Royal Society B, 275, 1279-1285.

Fischer, R., \& Van de Vliert, E. (2011). Does climate undermine subjective wellbeing? A 58-nation study. Personality and Social Psychology Bulletin, 37, 1031-1041.

Fought, J. G., Munroe, R. L., Fought, C. R., \& Good, E. M. (2004). Sonority and climate in a world sample of languages: Findings and prospects. CrossCultural Research, 38, 27-51.

Georgas, J., Van de Vijver, F. J. R., \& Berry, J. W. (2004). The ecocultural framework, ecosocial indices, and psychological variables in cross-cultural research. Journal of Cross-Cultural Psychology, 35, 74-96.

Halevy, N., Weisel, O., \& Bornstein, G. (2012). "Ingroup-love" and "outgrouphate" in repeated interaction between groups. Journal of Behavioral Decision Making, 25, 188-195.

House, R. J., Hanges, P. J., Javidan, M., Dorfman, P. W., \& Gupta, V. (Eds.). (2004). Culture, leadership, and organizations: The GLOBE study of 62 societies. Thousand Oaks, CA: Sage.

Huntington, E. (1945). Mainsprings of civilization. New York: Wiley.

Inglehart, R., \& Baker, W. E. (2000). Modernization, cultural change, and the persistence of traditional values. American Sociological Review, 165, 19-51. 
Inglehart, R., Basáñez, M., Díez-Medrano, J., Halman, L., \& Luijkx, R. (Eds.). (2004). Human beliefs and values: A cross-cultural sourcebook based on the 1999-2002 values surveys. Mexico: Siglo XXI Editores.

Inglehart, R., \& Welzel, C. (2005). Modernization, cultural change, and democracy. New York: Cambridge University Press.

Kenrick, D., Griskevicius, V., Neuberg, S., \& Schaller, M. (2010). Renovating the pyramid of needs: Contemporary extensions built upon ancient foundations. Perspectives on Psychological Science, 5, 292-314.

Kitayama, S., Conway, L. G., Pietromonaco, P. R., Park, H., \& Plaut, V. C. (2010). Ethos of independence across regions in the United States: The productionadoption model of cultural change. American Psychologist, 65, 559-574.

Kitayama, S., Ishii, K., Imada, T., Takemura, K., \& Ramaswamy, J. (2006). Voluntary settlement and the spirit of independence: Evidence from Japan's "northern frontier." Journal of Personality and Social Psychology, 91, 369-384.

Lazarus, R. S., \& Folkman, S. (1984). Stress, appraisal and coping. New York: Springer.

LePine, J. A., LePine, M. A., \& Jackson, C. L. (2004). Challenge and hindrance stress: Relationships with exhaustion, motivation to learn, and learning performance. Journal of Applied Psychology, 89, 883-891.

LePine, J. A., Podsakoff, N. P., \& Lepine, M. A. (2005). A meta-analytic test of the challenge stressor-hindrance stressor framework: An explanation for inconsistent relationships among stressors and performance. Academy of Management Journal, 48, 764-775.

Maslow, A. H. (1954). Motivation and personality. New York: Harper \& Row.

Milgram, S. (1974). Obedience to authority: An experimental view. London: Tavistock.

Murray, D. R. (2013). Cultural adaptations to the differential threats posed by hot versus cold climates. Behavioral and Brain Sciences, 36, 497-498.

Parker, P. M. (1997). National cultures of the world: A statistical reference. Westport, CT: Greenwood Press.

Parsons, K. C. (2003). Human thermal environments: The effects of hot, moderate and cold environments on human health, comfort and performance (2nd ed.). New York: Taylor \& Francis.

Podsakoff, N. P., LePine, J. A., \& LePine, M. A. (2007). Differential challenge stressor-hindrance stressor relationships with job attitudes, turnover intentions, turnover, and withdrawal behavior: A meta-analysis. Journal of Applied Psychology, 92, 438-454. 
Ritzer, G. (2004). The McDonaldization of society (rev. ed.). Thousand Oaks, CA: Pine Forge Press.

Schaller, M., \& Murray, D. M. (2011). Infectious disease and the creation of culture. In M. J. Gelfand, C. Chiu, \& Y. Hong (Eds.), Advances in culture and psychology (pp. 99-151). New York: Oxford University Press.

Taylor, T. G. (1937). Environment, race, and migration. Chicago, IL: University of Chicago Press.

Tooby, J., \& Cosmides, L. (1992). The psychological foundations of culture. In J. H. Barkow, L. Cosmides, \& J. Tooby (Eds.), The adapted mind: Evolutionary psychology and the generation of culture (pp. 19-136). New York: Oxford University Press.

UNDP (United Nations Development Programme). (2004). Human development report 2004. New York: Oxford University Press.

UNDP (United Nations Development Programme). (2010). Human development report 2010. New York: Palgrave Macmillan.

Van de Vliert, E. (2009). Climate, affluence, and culture. New York: Cambridge University Press.

Van de Vliert, E. (2011a). Bullying the media: Cultural and climato-economic readings of press repression versus press freedom. Applied Psychology: An International Review, 60, 354-376.

Van de Vliert, E. (2011b). Climato-economic origins of variation in ingroup favoritism. Journal of Cross-Cultural Psychology, 42, 494-515.

Van de Vliert, E. (2013a). Climato-economic habitats support patterns of human needs, stresses, and freedoms. Behavioral and Brain Sciences, 36, 465-480.

Van de Vliert, E. (2013b). White, gray, and black domains of cultural adaptations to climato-economic conditions. Behavioral and Brain Sciences, 36, 503-521.

Van de Vliert, E., \& Postmes, T. (2012). Climato-economic livability predicts societal collectivism and political autocracy better than parasitic stress does. Behavioral and Brain Sciences, 35, 94-95.

Vanhanen, T. (2009). The limits of democratization: Climate, intelligence, and resource distribution. Augusta, GA: Washington Summit Publishers.

Welzel, C. (2013). Freedom rising: Human empowerment and the quest for emancipation. New York: Cambridge University Press.

World Economic Forum (2005). The global competitiveness report 2004-2005. New York: Palgrave MacMillan. 
This text is taken from Human Ecology Review, Volume 21, Number 2, 2015, published 2015 by ANU Press, The Australian National University, Canberra, Australia. 